AperTO - Archivio Istituzionale Open Access dell'Università di Torino

Effects of biocontrol agents and compost against the Phytophthora capsici of zucchini and their impact on the rhizosphere microbiota

This is a pre print version of the following article:

Original Citation:

Availability:

This version is available http://hdl.handle.net/2318/1762465

since 2020-11-11T17:33:29Z

Published version:

DOI:10.1016/j.apsoil.2020.103659

Terms of use:

Open Access

Anyone can freely access the full text of works made available as "Open Access". Works made available under a Creative Commons license can be used according to the terms and conditions of said license. Use of all other works requires consent of the right holder (author or publisher) if not exempted from copyright protection by the applicable law. 
1 Effects of biocontrol agents and compost against Phytophthora capsici of zucchini and the

2 impact on the rhizosphere microbiota

3

4 Maria Alexandra Cucu ${ }^{\mathrm{a}, \mathrm{b}}$, Giovanna Gilardi ${ }^{\mathrm{b}}$, Massimo Pugliese ${ }^{\mathrm{a}, \mathrm{b}, \mathrm{c}}$, Ilario Ferrocino ${ }^{\mathrm{b}}$, Maria $5 \quad$ Lodovica Gullino ${ }^{\mathrm{a}, \mathrm{b}}$

6

$7{ }^{a}$ AGROINNOVA - Centre of Competence for the Innovation in the Agro-Environmental Sector,

8 Turin University, Largo P. Braccini 2, 10095, Grugliasco, Turin, Italy

$9{ }^{b}$ Agricultural, Forestry and Food Sciences Department (DISAFA), Turin University, Largo P.

10 Braccini 2, 10095 Grugliasco, Turin, Italy

$11{ }^{c}$ AgriNewTech srl, Via Livorno 60, 10144 Turin, Italy.

12

13

14

$15 *$ Corresponding author:

16 Dr. Maria Alexandra Cucu

17 Phone: +390116708544

18 Email: mariaalexandra.cucu@unito.it

19 
Four different biocontrol agents (BCA's) and two composts have been used in this study to evaluate their efficiency against Phytophthora blight of zucchini caused by Phytophthora capsici. The effects

31 of the BCA's and composts on the zucchini rhizosphere's microbiota were examined at the end of experimental trials from 2016 and 2017 in two farms under natural and artificially infested soils., Next generation amplicon sequencing technology and quantitative Polymerase Chain Reaction qPCR as targeted and untargeted approaches respectively, have been used. The abundance of $P$. capsici, measured for all the treatments over both years, decreased with respect to the untreated control, and it may be assumed that direct pathogen-beneficial microorganism interaction occurred. All treatments reduced the disease incidence by at least $50 \%$ in both sites under naturally or artificially infested soil and at both sampling times. The disease index was in accordance with the pathogen abundance. The development of microbiota and mycobiota was not affected by the BCA's, thus indicating that the tested treatments did not interact negatively with microbial communities, which in turn suggested a slow but good adaptation of the biocontrol agents to the environment. The combination of targeted and untargeted approaches may help to understand the effect of different BCA's on the development of Phytophthora capsici.

Keywords: Phythopthora capsici; BCA's; disease suppression; Next Generation Sequencing 
1. Introduction

54 Zucchini (Cucurbita pepo L.) is a very important crop from economically point of view (Jeffrey 2001; Paris and Maynard, 2008). The covered growing area in northern Italy is approximately 5,473 ha, with 1,326,811 tons of total production in open fields and under greenhouse conditions (ISTAT, 2017). This crop is often subjected to attacks by several soil-borne pathogens, one of which, Phytophthora capsici (Leon.), is a very serious agent of crown and root rot of cucurbit as well as of other crops (Hausbeck and Lamour, 2004; Lamour et al., 2012). Symptoms caused by P. capsici on zucchini have been observed extensively throughout Italy and are very serious in open fields (Garibaldi and Gullino, 2010).

The ability to develop fungicide resistance (Hausbeck and Lamour, 2004; Ploetz et al., 2002; Tamietti and Valentino, 2001), the existence of several physiological races and the lack of resistant cultivars (Sy et al., 2008; da Costa Ribeiro and Bosland, 2012), as well as the decreasing availability of fumigants (Colla et al., 2012) are making the disease control very difficult. Thus, there is a need for evolving environmentally friendly stratagems (Parra and Ristaino, 2001) such as Naing et al., 2014), Clitocybe nuda (Chen et al., 2012) and Aspergillus spp. (Kang and Kim, 2004). 
effect on the management of Phytophthora root and crown rot of bell pepper (Chae et al., 2006; Gilardi et al., 2013; Kim et al., 1997; Nunez-Zofio et al., 2011; Sang et al., 2010).

Biological control is often based on the rhizosphere competence which includes soil environment colonization of biocontrol agents (BCA's) alone, or mixed with composts (Garibaldi et al., 1989; Gupta et al., 2014; Lorito and Woo, 2015b; Philippot et al., 2013; Wallenstein, 2017; Bonanomi et al., 2018). Since rhizosphere represents the pivotal interface for plant roots and the beneficial microorganisms which have a very import role in plant health, understanding how BCA's and compost applications influence them under field conditions over several seasons of monoculture, may be helpful for the development of practices to suppress pathogens and for the success and fitness of the crop in the agro system.

In this study, the effectiveness of BCA's commercially available (Bacillus subtilis QST713 and Trichoderma gamsii ICC 012 + Trichoderma asperellum ICC 080) and experimental (Trichoderma sp. TW2 and a mixture of Trichoderma sp. FC7 and FC8), together with compost, has been evaluated under field conditions and over two years, in naturally and artificially infested soil conditions. The following objectives were proposed: i) the estimation of the pathogen and disease reduction following the use of BCA's and compost as treatments applied in pre-planting stage; ii) the evaluation of the extent of rhizosphere colonization by BCAs; iii) the evaluation of BCA's and compost impact may have on the rhizosphere microbiota.

2. Materials and Methods

\subsection{Layout of the field experiments}

The experiments were carried out under field conditions in Northern Italy in one experimental farm at Carmagnola $\left(44^{\circ} 88^{\prime} 55.188^{\prime \prime} \mathrm{N} 7^{\circ} 68^{\prime} 37.457^{\prime \prime} \mathrm{E}\right)$ as well as in a commercial farm, at Moretta

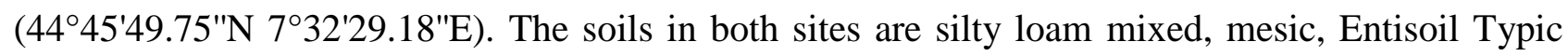
Ustifluvent (Carmagnola) and Entisoil Aquic Udifluvent (Moretta) (Soil Survey Staff, 2010). The principal difference between the sites is their $\mathrm{pH}$, which is almost neutral for Moretta $(\mathrm{pH}=6.85)$ 
and alkaline $(\mathrm{pH}=7.89)$ for Carmagnola. The studied soil sites are characterized by silt:sand:clay in

106 a ratio of $60: 30: 10 \%$ and $1.5 \%$ organic matter at Moretta, with Phythopthora capsici naturally 107 infested soil, and by silt:sand:clay $64: 24: 12 \%$ and $1.5 \%$ organic matter at Carmagnola, artificially 108 infested with a selected pathogenic isolate of $P$. capsici obtained from the crown tissues of affected 109 zucchini plants (100 g pathogen biomass per square meter).

110 In both trials carried out in the experimental farm from Carmagnola, a highly virulent strain of $P$. 111 capsici (PHC1/16) obtained from infected zucchini plants in a field in Northern-Italy was used. The 112 isolate was propagated by inoculation of a colonized agar-plug on to a sterile mixture of wheat113 hemp kernels $(2: 1 \mathrm{v} / \mathrm{v})$ in a 1-L flask kept at room temperature in the dark (Gilardi et al., 2016). The 114 15-day-old culture of the pathogen was mixed into the soil before planting the treated and untreated 115 seedlings. In order to achieve a uniform soil infestation, the pathogen biomass obtained was 116 incorporated in the soil 7 days before planting at $100 \mathrm{~g} / \mathrm{m}^{2}$ by rototilling at a depth of $1-20 \mathrm{~cm}$. Two 117 trials were also carried out in the Moretta commercial farm, naturally infested with the pathogen. 118 The site of the trials was selected because had a history of zucchini cultivation with 20 to $40 \%$ of 119 plant losses depending the years.

120 The field trials were conducted over two consecutive years, that is, 2016 and 2017 in order to 121 evaluate the efficacy of soil treatments applied in pre-planting starting from the nursery against $P$. capsici with different biocontrol agents (BCA's) such as Bacillus subtilis QST713 (Serenade, Bayer Crop Science, Italy) and Trichoderma gamsii ICC 012 + Trichoderma asperellum ICC 080 (Remedier, ISAGRO, Italy), which are commercially available. Experimental BCA's have been tested as well: Trichoderma sp. TW2 (AgriNewTech, Italy) (Cucu et al., 2018; 2020) and a mixture of Trichoderma sp. FC7 and FC8 isolated from suppressive soilless (Agroinnova, Italy) (Garibaldi et al., 2003). In addition, two composts, produced from green waste from a dynamic industrial treatment system, were used: a green compost (Ant's Compost V - CV, AgriNewTech, Italy) and 129 the same compost inoculated with Trichoderma sp. TW2 (Ant's Compost M - CM, AgriNewTech, 130 Italy) according to Pugliese et al., (2011). An untreated control was used to monitor P. capsici 
131 development, while metalaxyl-M (Ridomil gold, $480 \mathrm{~g} \mathrm{~L}$, Syngenta Crop Protection, Italy) as

132 reference chemical control at $0.48 \mathrm{~g}$ a.i. $\mathrm{L}$, label dose concentration, was applied by soil drenching

133 before planting. Summarized details of these treatments can be found in Table 1.

134 Zucchini seeds (cv. Ortano, Syngenta) were sown in 40-plug trays (3.4 cm diameter pots, $4 \mathrm{~L}$ of 135 soil, $53 \times 42 \mathrm{~cm}$ surface) containing a peat mixture substrate.

136 Three soil applications with BCAs were carried out on the plug trays between sowing and 137 transplanting (at the first true leaf stage) in a commercial nursery under glasshouse conditions at 138 temperatures of $20-24^{\circ} \mathrm{C}$. The BCAs were applied by spraying them onto the soil surface in a high 139 volume of water $\left(500 \mathrm{ml} \operatorname{tray}^{-1}\right)$, using a $1 \mathrm{~L}$ capacity hand sprayer. The composts were mixed at $14020 \% \mathrm{v} / \mathrm{v}$ at the tray level and immediately before sowing (T0).

141 The zucchini plants (15-day old) were transplanted at a density of 3 plants per square meter, drip 142 irrigated and grown according to the cultural practices adopted by commercial growers in the 143 region. The plots were arranged in a completely randomized block design, with five replicates per 144 treatment corresponding to 15 plants per replicate in trials carried out in 2016 and 20 plants per 145 replicate in trials carried out in 2017. The final disease rating was established 62 to 82 days after 146 transplanting on each plot by visually estimate the severity of Phytophthora crown rot symptoms of 147 all the plants present in each plot (Table 2). According to Padley et al. (2008), the disease severity 148 (DS) scale was as follows: $0=$ healthy plant, $25 \%=$ initial leaf chlorosis, $50 \%=$ severe leaf 149 chlorosis and initial symptoms of wilting during the hottest hours of the day, $75 \%=$ severe wilting 150 and severe symptoms of leaf chlorosis, $100 \%=$ plant totally wilted, leaves completely necrotic. 151 Symptoms were visually estimated at the final evaluation for each plant using a scale rate as follow 152 from 0 to 5.: $0=$ no symptoms, healthy plants; $1=1$ to $30 \%$ leaves slight wilted (midpoint $15 \%$ ); $2=31$ 153 to $50 \%$ foliar wilting with crown lesion (midpoint $40 \%$ ); $3=51$ to $70 \%$ of plant is partially collapsed 154 (midpoint $60 \%$ ); $4=71$ to $90 \%$ of plant is collapsed (midpoint $80 \%$ ): 5=over $90 \%$ dead plant 155 (midpoint 95\%). Disease severity was expressed by using the formula $\left[\sum\left(\mathrm{n}^{\circ}\right.\right.$ plants $\left.\times \mathrm{x} 0-5\right) /($ total 156 no of plants recorded)] with x 0-5 corresponding to the value reported. 
158 The influence of soil-treatments with BCA's and compost on indigenous microbial communities was studied at the rhizosphere level by collecting samples from both experimental sites at the end of the trials (November 2016 and 2017), as described elsewhere (Cucu et al., 2018). Briefly, one composite rhizosphere sample per plot consisted of the roots of five randomly selected zucchini plants. The roots were shaken vigorously to remove the soil particles not tightly adhering to them.

163 The rhizosphere soil was gently scraped off with sterile forceps and transferred into sterile sampling bags. Each treatment consisted of three biological replicates, which were kept on ice. The samples were then placed in plastic bags, kept on ice and transported to the laboratory.

2.3. Microbial community analysis

2.3.1. Rhizosphere soil DNA extraction

A NucleoSpin ${ }^{\circledR}$ Soil kit (Macherey-Nagel GmbH \& Co. KG, Düren, Germany) was used, according to the manufacturer's instructions, for the rhizosphere soil genomic DNA extraction. Extraction was conducted on $0.6 \mathrm{~g}$ sample material. DNA quantity and purity were measured using a NanoDrop ND-1000 (NanoDrop Technologies, Wilmington, DE, USA) and standardized at $10 \mathrm{ng}$ $173 \mu 1^{-1}$.

\subsubsection{Microbial structure}

Amplicon target sequencing

177 Total genomic DNA extracted from the rhizosphere samples was used as template to amplify the 178 V3-V4 region of 16S rRNA (primers 16S-F (5'-TCG TCG GCA GCG TCA GAT GTG TAT AAG 179 AGA CAG CCT ACG GGN GGC WGC AG-3') and 16S-R (5'-GTC TCG TGG GCT CGG AGA 180 TGT GTA TAA GAG ACA GGA CTA CHV GGG TAT CTA ATC C-3')) (Klindworth et al., 181 2013) as well as the D1 domain of the 26S rRNA gene (primers LS2-MF 5'- 
183

et al., 2018). The PCR mix was done in a total volume of $25 \mu \mathrm{l}$ as follows: $12.5 \mu 1$ of the $2 \times$ Kapa HiFi HotStart ReadyMix Taq (Roche, Milan, Italy), $5 \mu$ l of each primer $(1 \mu \mathrm{M})$ and $2.5 \mu 1$ DNA as a template.

The PCR mix was subjected to the following amplification cycling : $95^{\circ} \mathrm{C}$ for 3 minutes; 30 cycles of: $95^{\circ} \mathrm{C}$ for 30 seconds, $55^{\circ} \mathrm{C}$ for 30 seconds, $72^{\circ} \mathrm{C}$ for 30 seconds and then $72^{\circ} \mathrm{C}$ for 10 minutes. Amplicons were purified according to the Metagenomic sequencing library preparation of Illumina. Nextera XT Index Kit (Illumina Inc. San Diego. CA) was used based on manufacturer's instructions, to tag each sample. After the 2 nd clean up stage, the amplicons were quantified using a QUBIT dsDNA Assay kit and equimolar amounts of amplicons from different samples, belonging to the same target gene, were pooled. The pooled libraries (16S and 26S) were run on an Experion workstation (Biorad, Milan, Italy) for a quality analysis prior to sequencing. The denaturated pool library (with $0.2 \mathrm{~N} \mathrm{NaOH}$ ) was combined with $20 \%(\mathrm{v} / \mathrm{v})$ of denatured $12 \mathrm{pM}$ PhiX, prepared according to the Illumina guidelines. The sequencing was performed with a MiSeq Illumina instrument (Illumina), with V3 chemistry, and 250 bp paired-end reads were generated, according to the manufacturer's instructions.

\section{Bioinformatics analysis}

After sequencing, FLASH software (Magoc et al., 2011) was used to join the paired end reads. Any joined reads shorter than $300 \mathrm{bp}$ were discarded using PRINSEQ. The data were analyzed through QIIME 1.9.0 software (Caporaso et al., 2010). Centroid sequences were used from each Operational Taxonomic Unit (OTU) cluster for the $16 \mathrm{~S}$ data to assign a taxonomy against the Greengenes $16 \mathrm{~S}$ rRNA gene database, version 2013, while the in-house database from Mota-Gutierrez et al. (2018) was used for the $26 \mathrm{~S}$ data.

For avoiding biases, due to different sequencing scales, each dataset was reduced at the lowest number of reads: the $26 \mathrm{~S}$ data were rarefied at 11808 sequences, while the 6285 sequence was chosen for the 16S data. Contamination of chloroplasts was removed from the 16S OTU tables. 
The 26S OTUs tables generated through QIIME showed the highest taxonomy resolution for the

210 species or genus. The order or class level was instead used for the $16 \mathrm{~S}$ data. The taxonomy was 211 double-checked using the BlastN search tool (http://www.ncbi.nlm.nih.gov/blast/) to confirm the 212 taxonomy assignment.

213 The data on microbial communities structure were analyzed using the $\mathrm{R}$ software (www.r214 project.org). The number of different taxa was estimated by sample coverage and microbial $\alpha$ 215 diversity assessed by Chao1 index. The taxa richness and evenness was calculated by Shannon 216 diversity index, using the diversity function of the vegan package of R (Dixon, 2003). Beta diversity 217 of $16 \mathrm{~S}$ data used the phylogenetic distances to compare samples associated with multivariate 218 statistical analysis (Principal coordinate analysis) based on Weighted and Unweighted UniFrac 219 distance matrixes. Anosim and Adonis statistical test, through the vegan function in the $\mathrm{R}$ 220 environment were used for the $16 \mathrm{~S}$ data to find any differences between samples, using the 221 phylogenetic distances matrix. A non-parametric Pairwise Wilcoxon test was used, when appropriate, to determine any significant differences in the alpha diversity index or in OTU abundance. Principal component analysis (PCA), based on OTU abundance, was performed and the results were plotted using the dudi.pca function of the made4 package of R. Hierarchical clustering heatplots were obtained, through the made4 package, using the weighted pair group method together with the arithmetic mean (WPGMA) method. Spearman's pairwise correlations were assessed between the taxa and chemical parameters using the $\mathrm{R}$ package psych. The $\mathrm{P}$ values were adjusted for multiple testing using the Benjamini-Hochberg procedure, which assesses the false discovery rate (FDR). Box plots were used to represent the interquartile range between the first and 230 the third quartiles, with the error bars showing the lowest and the highest values. qPCR assays were used to determine the abundance of $P$. capisci (Lan et al., 2013), Bacillus spp. 234 (Gao et al., 2011) and Trichoderma spp. (Hagn et al., 2007) with the StepOnePlus ${ }^{\mathrm{TM}}$ Real-Time 
PCR System (Applied Biosystems, Foster City, CA, USA). Fungal chitinase chiA gene, and the nitrifiers (i.e., bacterial ammonia monooxygenase amoA gene - AOB and archaeal amoA gene AOA) have been also evaluated. Table S1 contains a description of the primer sets and amplification details.

The standards for the qPCR assays were generated as described by Cucu et al. (2017) from amplicons of each target gene, purified (Invisorb Fragment CleanUp, Stratec Molecular GmbH, Berlin, Germany) and ligated in Strata-Clone PCR cloning vector pSC-A (Strataclone PCR Cloning Kit, Agilent Technologies Inc.); the products of the ligation were then transformed into StrataClone SoloPack competent cells (Agilent Technologies Inc.). The specificity of the amplicons used as qPCR standards was controlled and the Plasmid DNA was isolated (GenElute ${ }^{\mathrm{TM}}$ Plasmid Miniprep Kit, Sigma-Aldrich, St. Louis, MO, USA) from standard clones and quantified as described above.

P. capsici, BCA's, and the bacterial and archaeal amoA abundances were determined in a final volume of the qPCR reaction mixtures of $25 \mu \mathrm{l}$, while the chiaA gene abundance in $20 \mu \mathrm{l} .10 \mathrm{ng}$ DNA template were used for all quantification reactions. As described earlier by Cucu et al. (2018), the qPCR cocktail had a 1x Power SYBR green master mix (Applied Biosystems), $0.12 \mu \mathrm{M}$ of each primer (Table S1) for P. capsici $0.32 \mu \mathrm{M}$ for the BCA's, AOB and AOA and $0.4 \mu \mathrm{M}$ for the chiA gene.

The quantifications were done with three replicates across plates, while standards were run in duplicate and in 10-fold serial dilutions. Prior quantifications, the best DNA dilution was tested to reduce any inhibitory reactions. Amplification efficiency ranged from 96\%, (BCA's and chiA gene) to $95.3 \%$ and $99.1 \%$ for $\mathrm{AOB}$ and AOA, respectively tor the nitrifiers. The $\mathrm{R}^{2}$ was always $\geq 0.98$.

Melting curves of the amplicons were generated to guarantee the specificity of the reaction and then the amplification products were checked on $1 \%$ agarose gel. Always the size of the amplicons was as previously reported by the given protocols (see Table S1). StepOne ${ }^{\mathrm{TM}}$ software, version 2.2 (Applied Biosystems) was used to calculate the gene copy number and the data were normalized and presented in tables as log copy $/ \mathrm{g} \mathrm{dw}^{-1}$. 
261 The data on gene abundance and on the chemical properties of the soil were subjected to a linear 262 mixed model, with time considered as the random variable, using the Statistical Analysis Software 263 program (SAS V 9.2, SAS Institute Inc., North Carolina, USA). The impact of different treatments 264 on the abundance of the considered genes, on the rhizosphere chemical properties and on disease severity were checked out. The Levene test was used to verify the homogeneity of variance, and Shapiro-Wilk test was chosen to check the normality on the residuals; the DS data were arcsin transformed when not normally distributed, while the data from microorganism abundance were log-transformed, and normality checked again. Univariate ANOVA (SPSS 24.09) was used for the data set analyses, and the means were separated by Tukey's multiple comparison test $(\mathrm{p}=0.05)$. The statistical analysis included the treatment, year and treatment $\times$ year. A least square means comparison between treatments was conducted using Tukey's range test $(p<0.05)$. Pearson linear correlation analyses were conducted, and the results were visualized to establish linearity in the SAS COR procedure in order to relate the abundance of the target genes (dependent variables) to the chemical properties of the soil (independent variables).

\subsection{Geo - chemical characterization of the rhizosphere samples}

The fresh rhizosphere samples were homogenized, passed through a $2 \mathrm{~mm}$ sieve, stored at $4^{\circ} \mathrm{C}$ and analyzed within $24 \mathrm{~h}$. All the samples were split into two. One part was analysed at the Regional Chemistry Laboratory (Turin, Italy) for humidity, $\mathrm{pH}$, total $\mathrm{N}(\mathrm{TN})$, inorganic $\mathrm{N}$ as nitrate $\left(\mathrm{NO}_{3}{ }^{-}\right)$ and ammonium $\left(\mathrm{NH}_{4}{ }^{+}\right)$, total phosphorus $(\mathrm{Pt})$ and available phosphorus (Pav), while the second part was used for molecular investigations.

282 The method for measuring $\mathrm{pH}$ was in water suspensions with solid: liquid ratio of 1:2.5. A Leco Tru 283 Spect $\mathrm{CN}$ automatic analyzer was used for the total nitrogen (TN) quantification. Inorganic 284 nitrogen, ammonium $\left(\mathrm{NH}_{4}{ }^{+}\right)$and nitrate $\left(\mathrm{NO}_{3}{ }^{-}\right)$using standard colorimetric techniques by means of 285 a continuous flow auto-analyzer (Alliance Evolution II). The total phosphorus (Pt) was determined 286 by means of 'ICP Varian mod. Liberty LR', after microwave based digestion with hydrogen 
peroxide, hydrochloric acid and nitric acid, filtration and dilution. The available $\mathrm{P}$ (Pav) was

288 determined by means of the molybdenum blue method (Olsen et al., 1954), modified for continuous 289 flow colorimetric analysis (Alliance Evolution II).

\section{Results}

\subsection{Disease severity (DS)}

293 The obtained results showed that the application of BCAs and certain organic matter can effectively suppress soil pathogens and reduce the disease. The disease severity (DS) in the non-treated control plots was higher in Carmagnola, where the soil was artificially infested with the pathogen, than in Moretta for both years (Table 2). During 2016, all the treatments based BCAs and compost significantly reduced the disease from 48 to $62 \%$ in the Carmagnola site and from 52 to $80 \%$ in the Moretta site, compared to the untreated plots (Table 2). In 2017, the artificial infestation of soil with the pathogen at the Carmagnola site produced a greater disease severity (DS $78 \%$ in the untreated control) resulting in a significant Phytopthora crown rot reduction between 32 to $49 \%$ provided by all the treatments, apart from the Trichoderma spp. T and TW2 treatments. While, in the Moretta site, under a low disease pressure (DS $28 \%$ in the untreated control) all the tested treatments provided a significant disease reduction from 50 to $82 \%$. The reference chemical treatment based metalaxyl-M was the most effective, reducing the DS by $56-78 \%$ in Carmagnola and by $94-99 \%$ in Moretta in both years. The efficacy of the two composts (CV and CM) was statistically similar to that of the chemical fungicide in both locations, reducing the DS by $56-59 \%$ and $45-49 \%$ in 307 Carmagnola and by $69-80 \%$ and $73-82 \%$ in Moretta, respectively. (Table 2).

\subsection{Microbial diversity}

310 The microbiota and mycobiota diversity in the two sites for the two different years was 311 characterized by $16 \mathrm{~S}$ and $26 \mathrm{~S}$ rRNA gene sequencing, obtained from gDNA extracted directly from 312 the rhizosphere soil samples. The DNA concentration which ranged between $82-100 \mathrm{ng} / \mathrm{g} \mathrm{dw}^{-1}$ for 
313 Moretta and $55-83 \mathrm{ng} / \mathrm{g} \mathrm{dw}^{-1}$ for Carmagnola, in both years, had the ratio of the absorbance at $314260 \mathrm{~nm}$ and $280 \mathrm{~nm}$ of $\sim 1.8$, assessing a "pure" DNA. Overall, 1,907,342 and 3,849,188 high 315 quality reads were analyzed for $16 \mathrm{~S}$ and $26 \mathrm{~S}$, respectively. The alpha-diversity indexes (Shannon, 316 Chao1 diversity index) and the number of species observed on the basis of OTUs of $97 \%$ identity, 317 are shown in Figure 1A (16S) and Figure 1B (26S). Anosim and Adonis statistical test performed 318 on $16 \mathrm{~S}$ as well as $26 \mathrm{~S}$ showed no difference for the different BCA's treatments and composts in the 319 two soils in the two years $(\mathrm{P}>0.05)$.

320 As far as the 16S data are concerned, the Carmagnola 2017 soil displayed a significantly higher 321 microbial diversity and richness $(\mathrm{P}<0.001)$ than Carmagnola 2016 and than the other site. 322 Moreover, the Moretta 2017 samples showed higher richness than the Moretta 2016 ones $(\mathrm{P}<0.05)$ 323 - see Figure 1A.

324 As for the mycobiota (Figure 1B), it was possible to observe that the Chaol index (an estimator of 325 species richness) and the number of observed OTUs were higher in the Moretta samples than in the 326 Carmagnola ones ( $\mathrm{P}<0.001)$. However, no differences were observed between Carmagnola 2016 327 and Carmagnola 2017 or between Moretta 2016 and Moretta 2017. It should be pointed out that the 328 different treatments did not affect the microbial diversity.

329 Using a Principal Coordinate analysis (PCoA, Fig. 2) of the weighted UniFrac distance matrix, we 330 observed a clear separation of the microbiota between Carmagnola 2016 vs. Carmagnola 2017 and 331 Moretta 2016 vs. Moretta 2017 (ANOSIM statistical test $\mathrm{P}<0.001$ ) for the beta diversity 332 calculation of the $16 \mathrm{~S}$ data. No differences were observed between Carmagnola 2016 and Moretta 333 2016. Samples from these two sites from the same year clustered together and were well separated 334 from the others (Fig. 2).

335 A similar trend was observed for the mycobiota populations. The principal component analysis 336 (PCA), based on the 26S OTU table, clearly showed a separation of Carmagnola 2017 from the 337 other site, while a distribution of the other samples was less marked (ANOSIM statistical test P < 
338 0.001) (Figure S1). No differences were observed when the different soil treatments were taken into 339 account.

\section{2. a Microbiota composition}

342 The relative abundances of the bacterial taxa were analyzed at a class level to show the 343 development of the microbiota over time, in both years, and across sites. A total of 34 classes, with 344 a relative abundance of $0.2 \%$ in at least 10 samples, were observed (Table 3 ). When the 345 Carmagnola site was considered in 2016 and 2017 (Table 3), the microbiota were dominated by the 346 presence of Actinobacteria (median value of 6 and 13\% of the relative abundance, respectively), Alphaproteobacteria (11 and 13\%), Bacilli (5 and 7\%), Betaproteobacteria (6 and 4\%), Chloroflexi

348 (3 and 5\%), Deltaproteobacteria (5 and 4\%), Phycisphaerae (5 and 3\%), Planctomycetia (9 and 349 6\%) and Thermoleophilia (3 and 6\%) - see Table 3.

350 The same trend was observed for the Moretta samples (Table 4), where Actinobacteria showed a 351 relative abundance, with a median value of 6 and 13\% in 2016 and 2017, respectively; 352 Alphaproteobacteria (12 and 12\%), Bacilli (3 and 7\%), Betaproteobacteria (5 and 4\%), Chloroflexi 353 (3 and 5\%), Deltaproteobacteria (5 and 4\%), Gammaproteobacteria (7 and 4\%), Phycisphaerae (6 354 and 4\%), Planctomycetia (5 and 7\%) and Thermoleophilia (2 and 6\%).

355 We observed a specific microbiota signature among the variables from a the pairwise comparison of 356 the sites and the years. In particular, Actinobacteria, Bacilli and Chloroflexi were found to be 357 associated (FDR < 0.05) with Carmagnola 2016 and Moretta 2016; Betaproteobacteria, 358 Deltaproteobacteria and Phycisphaerae with Carmagnola 2017 and Moretta 2017; 359 Alphaproteobacteria was observed to be associated with Carmagnola 2016 and 360 Gammaproteobacteria with Moretta 2017 (Figure S2). 
363 A total of 58 taxa, with a relative abundance of $0.2 \%$ in at least 10 samples, were observed (Tables 364 S2 and S3). When only the main fungi that occurred with a higher percentage than 5\% were taken 365 into account, the presence of Alternaria tenuissima (median values of 1 and $9 \%$ of the relative 366 abundance in 2016 and 2017, respectively), Cladosporium cladosporioides (median value sof 4 and 367 9\%), Fusarium oxysporum (6 and 3\%), Leotiomycetes (19 and 2\%) and Pseudeurotium zonatum 368 (28 and 1\%) was observed in the Carmagnola site in 2016 and 2017 (Table S2)

369 The Moretta samples (Table S3) were dominated by the presence of Aspergillus oryzae (median 370 values of 5 and $1 \%$ of the relative abundance in 2016 and 2017, respectively), Leotiomycetes (13 371 and 23\%) and Pseudeurotium zonatum (34 and 35\%).

372 A specific mycobiota signature between the sites and the years was observed from the pairwise 373 comparison (Figure S3, FDR < 0.05). In particular, it was observed that Alternaria tenuissima and 374 Cladosporium cladosporioides were associated with the Carmagnola site in 2017, Aspergillus oryzae and Fusarium oxysporum with the Carmagnola site in 2016, Leotiomycetes were associated with both sites in 2016 and 2017 and Pseudeurotium zonatum was associated with the Carmagnola site in 2016 and Moretta 2016 (Figure S3, FDR < 0.05).

\subsection{Microbial abundance}

3.3a Abundance of soil-borne P. capsici by means of $q P C R$

381 All the treatments resulted in a significant pathogen reduction $(\mathrm{p}<0.05)$, compared to the untreated control (C), in both the Moretta and Carmagnola sites, in both years. The quantity of the pathogen in the Moretta rhizosphere samples was lower after the RM treatment in both years, while it was 384 lower in the Carmagnola site after the RM treatment in 2016 and 2017 respectively (Table 5).

\section{3b Abundance of antagonists $N$ - cycling genes by means of $q P C R$}

All the treatments resulted in a significant boost of Bacillus spp. and Trichoderma spp., compared 
treatment and lower after the Trichoderma sp. - T treatment and Trichoderma sp. - TW2 in the

390 Moretta samples in 2016 and 2017 respectively, while the Bacillus spp. abundance was higher after 391 the Bacillus - SM treatment and lower after the Trichoderma sp. - TW2 treatment for the 392 Carmagnola counterparts after both years (Table 6).

393 Trichoderma spp. abundance significantly enhanced after all the Trichoderma sp. treatments, 394 compared with the untreated control - $\mathrm{C}$ for both sites and both years (Table 6).

395 The same trend was observed for chiA gene abundance, which significantly enhanced after all the Trichoderma spp. treatments, compared with the untreated control - C and the Bacillus treatment $\mathrm{SM}$ in Moretta samples after both years. However, the enriched compost - CM had the highest abundance of the chiA gene. Carmagnola samples were characterised by the same situation, but with the highest abundance of chiA gene after Trichoderma sp. - TW2 in 2016 and enriched compost $400 \quad \mathrm{CM}$ in 2017 (Table 7).

401 The ammonia-oxidizing bacterial (AOB) and archaeal (AOA) gene abundance was significantly 402 influenced by treatments. Both sites were characterized by the increase of AOB and AOA 403 abundance in all treatments comparing with the untreated control. In general, the abundance of 404 AOB was higher in rhizosphere samples from Carmagnola site, while the abundance of AOA was 405 higher in rhizosphere samples from Moretta site (Table S4 and Table S5).

\subsection{Chemical properties}

408 The $\mathrm{pH}$ values of rhizosphere samples generally were lower for Moretta site than for Carmagnola 409 ones and ranged from between 5.36 to and 6.23 and 6.20 to 7.78 respectively. The untreated control 410 was characterized by higher $\mathrm{NH}_{4}{ }^{+}, \mathrm{NO}_{3}{ }^{-}$concentrations than all the treatments. On the other hand, 411 the Pt and Pav contents were lower (Table S6). 
415 By plotting the correlation between chemical determination, microbiota and mycobiota in 416 Carmagnola samples (Figure S4A; FDR < 0.05) the results showed more relationships between the 417 taxa and $\mathrm{TN}, \mathrm{NO}_{3}{ }^{-}$and $\mathrm{NH}_{4}{ }^{+}$with respect to Moretta samples (Figure S4B; FDR < 0.05). By 418 plotting the correlation between chemical determination, microbiota and mycobiota in Moretta 419 samples for both years (Figure S4B; FDR < 0.05) the results showed more relationships between 420 the taxa and $\mathrm{pH}$ as well as between the taxa and the pathogen abundance.

b. Pearson correlations between Bacillus and Trichoderma abundances and chemical parameters In general, the correlations with $\mathrm{pH}$ were positive, with $\mathrm{r}$ coefficients ranging from 0.55 to 0.85 (p < 0.001) for the rhizosphere samples from Moretta e Carmagnola sites. The correlations were negative between Bacillus and Pt and Pav and positive for Trichoderma (Table S7).

4. Discussion

Four biocontrol agents and two compost were chosen to control soil borne pathogens as P. capsici.

It is well known that their effect is relative, depending on the plant host, involved pathogen species and the characteristics of the applied treatments (Bonanomi et al., 2006). Even more, the interactions among beneficial microorganisms newly introduced into the soil system, as single strains or in microbial consortium, with indigenous rhizosphere microbial populations and the plant usually vary with the environmental conditions (Mendes et al., 2013).

The results of the field experiments showed that the all treatments reduced the disease severity and were particularly effective against the pathogen, in comparison to the untreated control, (Heydari and Pessarakli, 2010; Noble and Coventry 2005; Pugliese et al., 2015). The findings were in line with the fact that pathogens populations in the soils could be reduced by biocontrol agents (Huang et al., 2011; Wei et al., 2011) and suppressive compost (Cucu et al., 2018). Similarly, previous studies showed several bacilli strains being effective against Phytophthora blight caused by $P$. 
441 capsici on squash (Zhang et al., 2010; Gilardi et al., 2015) and on pepper (Sang et al, 2013). Even 442 more, the mixture of organic substrates and BCA's may induce the suppression of plant pathogens 443 through different mechanisms. Blaya et al. (2013), Cao et al. (2011) and Hoitink et al. (2006) 444 hypothesized the presence of direct interactions as competition for nutrients and space, the 445 production of antibiotics, mycoparasitism and indirect interactions, such as systemic and acquired 446 resistance (ISR and SAR). Nevertheless, the disease severity was greater at higher $\mathrm{pH}$ conditions 447 which was in agreement with previous studies involving P. capsici as pathogen (Muchovej et al., 448 1980).

449 Through the use of the targeting approach, a reduction in $P$. capsici abundance was observed as a 450 result of all the applied treatments, thereby assuming that a direct pathogen-BCA's interaction 451 occurred. This effect could be due to antibiosis or/and mycoparasitism process induced by 452 Trichoderma spp. hydrolytic enzyme secretion, which may have caused the hydrolysis of the 453 pathogen cell wall, or antibiotic compound production (Woo et al., 2006, Lorito and Woo, 2015a). 454 A higher abundance of Trichoderma spp. and of the chiA gene in all the treatments was observed 455 highlighting the positive effect of Trichoderma spp. when used as a biocontrol agent or in 456 combination with organic material as pointed out by Lorito et al. (2010), Hermosa et al. (2012), and 457 Cucu et al. (2018). This result in corroboration with good relationships with rhizosphere chemical 458 parameters evidenced the fact that Trichodema spp. readily transfers and absorbs soil nutrients (e.g., 459 phosphate - Tandon et al., 2018) and is more efficient and competitive that many other fungi. In 460 consequence, it can therefore be used effectively to improve the soil structure and promote the 461 establishment and maintenance of other beneficial microorganisms (Benitez et al., 2004). The 462 targeting analyses showed also a good feedback of Bacillus spp. after all the treatments. The same 463 response was observed by Cucu et al. (2018) in a Fusarium oxysporum - lettuce pathosystem, 464 evidencing a good feedback of indigenous rhizosphere Bacillus populations. In general, Bacillus 465 spp. was found to be extremely effective in plant disease suppression as it forms a stable and 466 extensive biofilm (Bais et al. 2004) composed of secreted antifungal compounds, such as surfactin, 
bacillomycin and microlactin, which protect plants from attack by soil-borne pathogens (Bais et al. 468 2004; Yuan et al. 2012). Even more, Yang et al. (2012) and Sid et al. (2003) reported that most species of Bacillus were able to inhibit the mycelia growth of $P$. capsici effectively "in vitro". Through the use of the un-targeting approach (amplicon based sequencing), it was shown also that the different BCA's and compost treatments did not affect the composition of the resident microbiota and mycobiota. This implied that the used treatments did not have any effect on the total microbial communities reflecting the great ecological stability of the rhizosphere (Thébault and Fontaine, 2010). In turn suggested a slow but good adaptation of the BCA's to the environment. Anyway, the observed differences among sampling dates may suggest that the composition of the soil microbial community might have been altered by differences in temperature and precipitation, as response of the microbial groups to environmental variables.

Actinobacteria, Bacilli and Chloroflexi were the most abundant bacterial phyla in both sites in 2016, while Betaproteobacteria, Deltaproteobacteria and Phycisphaerae were observed in both of the studied sites in 2017; Alphaproteobacteria was associated with the Carmagnola site in 2016, while Gammaproteobacteria was associated with the Moretta site in 2017. Soil microbial communities structure was shaped by a multitude of factors, including environmental parameters as suggested by the correlation analyses of soil chemical properties namely $\mathrm{TN}, \mathrm{NO}_{3}{ }^{-}{ }^{-} \mathrm{N}, \mathrm{NH}_{4}{ }^{+}-\mathrm{N}$ available $\mathrm{P}$ and the relative abundances of different microbial populations across the considered sites, especially for the Carmagnola rhizosphere soil. This observed differences could be attributed to the difference in the soil $\mathrm{pH}$, as it is generally considered as the best predictor of the microbial community composition and diversity (Fierer and Jackson, 2006). The similarity of the chemical and physical 488 characteristics of the individual soil sites permitted to consider independently the $\mathrm{pH}$ effects. This was confirmed by the abundance data of populations of ammonia-oxidizing bacteria and archaea. The results showed an elevated amount of ammonia-oxidizing bacteria, mainly Betaproteobacteria, with respect to the untreated control especially at higher $\mathrm{pH}$ of Carmagnola site, in line with what previously reported (Nicol et. al., 2008). On the opposite a higher abundance of archaeal ammonia 
oxidizers was observed in samples from Moretta site this suggesting a potential niche differentiation between the ammonia oxidizers as indicated also by the relationships with chemical properties (Figure S4A and B). Although the increase of ammonia-oxidizing bacteria and archaea abundance with respect to the untreated control may suggest a possible contribution of these microorganisms to the disease reduction, further research in regard must be taken in consideration.

The Moretta site showed a predominance of relationships between the $\mathrm{pH}$ and microbial taxa (Figure S4B). Prior to the use of NGS, Fierer and Jackson (2006), using Terminal Restriction Length Polymorphism, identified a maximum of microbial diversity for a neutral $\mathrm{pH}$. Rousk et al. (2010) extended this finding using experimental plots. Sequences that were classified as belonging to Gammaproteobacteria were shown to correlate negatively with $\mathrm{pH}$, a result that was in contradiction with what Postma et al. (2011) reported. On the other hand, the relative abundance of Actinobacteria was found to be positively correlated with pH. Lauber et al. (2009) also reported clear shifts in the bacterial-phylum level, with the relative abundance of Actinobacteria increasing as the $\mathrm{pH}$ value increased.

The soil artificially infested with $P$. capisici showed a somewhat increased abundance of Actinobacteria. Ros et al. (2016) observed the same phenomenon after seedling infection by $P$. nicotianae. This result, together with good correlations with the soil properties (Figure S4A), indicated that the highlighted microbial communities could play a strategic role in the organic materials decomposition and in the nutrient cycle, as evidenced by Steger et al. (2003). Although these microorganisms have a great ability to produce antibiotic-like compounds (McKellar and Nelson, 2003), the results indicated that they did not have a positive influence on plant disease suppression in the case of an artificial infestation since no relationship with $P$. capsici was found. The opposite was observed for the natural infestation, result evidenced by correlations between Actinobacteria and pathogen. Thampi and Bhai, (2017) reported some Actinobacteria strains as potential antagonists against $P$. capsici, after their isolation and characterization from rhizosphere samples of black pepper. However, these results might be contradictory as Sutherland and 
Papavizas (1991) reported, in a very early "in vitro" study, that Actinobacteria, which infested oospores of $P$. capsici, were not effective under greenhouse conditions and didn't control the crown rot of pepper. Cuesta et al. (2012) also reported that the presence of Actinobacteria is typical of suppressive substrates. Bonanomi et al., (2010) concluded that disease suppression was only correlated with Actinobacteria in a small number of experiments. However, the here presented results suggested that enlarged populations of Actinomycetes might lead to a favourable environment for biocontrol strains against $P$. capsici on zucchini.

Bacillus was found as some of the most abundant genera in all the treatments, the sequencing results being supported by the quantitative analyses. The observed relatively high abundance of Bacilli phyla was in accordance with several other studies which reported the potential antagonism of Bacillus species against P. capsici. For example, Lee et al., (2008), on the basis of 16S rDNA 530 sequencing, showed that the most effective isolates with antagonistic activity against $P$. capsici were Bacillus subtilis. In addition, differences were observed between the studied sites regarding the relationships between the soil parameters and the pathogen, results which indicated that the presence of Bacillus was induced by a natural infestation with the pathogen at a neutral $\mathrm{pH}$. This may explain the effectiveness of Bacillus spp. in the presence of a native pathogen. The Bacillus treatment was also effective in the case of artificially infested soil, as evidenced by Li et al. (2019). The good correlations between the relative abundance of Bacillus and the soil properties in the artificially infested soil indicated the important effects of Bacillus spp. on nutrient availability and plant growth, as already described by Charest at al. (2005) and Garcia et al. (2011).

539 The interaction between $P$. capsici-BCA's strains at the rhizosphere level showed the presence of 540 Alphaproteobacteria enrichment and, in particular, the more relative abundance of Bradyrizobium, 541 Mesorhizobium, Hypomicrobium, thus indicating that they may be involved in the disease 542 suppression of $P$. capsici. As pointed out by Compant et al., (2010), rhizobia may play a very 543 important role in biocontrol, due to the secretion of antibiotics and hydrogen cyanide (HCN), and 544 also due to the production of siderophores. 
545 The fungal community was characterised by the abundant presence of Ascomycota after all the 546 treatments administered including the compost ones, as also shown by Blaya et al., (2016) and 547 Langarica et al., (2014). The variation of the mycobiota at a phylum level was probably principally 548 due to the type of substrate rather than to the pathogen infection. It should be considered that 549 different genera, such as Trichoderma spp. and Fusarium spp., were abundant in all the treatments, 550 independently of the pathogen infection. Trichoderma, Fusarium and Cladosporium species have 551 been considered as biological control agents (Kaur et al., 2010, Lopez-Mondeja et al., 2010) and 552 can be speculated to have contributed to the disease suppression to a great extent. The fungal 553 species belonging to Leotiomycetes (Wang et al., 2006) have the potential to improve nutrient 554 acquisition and combat pathogenic taxa, maintaining cooperative metabolic associations with other 555 species. Species of Aspergillus and Pseudoritium, the potential phosphate-solubilising fungal genera, were also detected in this study. Nevertheless, further research must be considered to better understand the functional composition of fungal community as a wide range of fungi may be involved effectively in the pathogen control. In addition, the temperature, soil moisture and soil type must be taken into account as this are among the most import factors that affect the 560 composition and structure of a microbial community (Spadaro and Gullino, 2005; Cregger et al., $5612015)$.

562 However, to better understand the effects of the different used treatments, it is necessary to focus on 563 the functional mechanism induced by the interaction of the pathogen with the BCA's newly 564 introduced into the system and dictated by the chemistry soil parameters, particularly the $\mathrm{pH}$. 565 Hence, further studies are necessary considering several soil types characterized by contrasting 566 physico-chemical parameters.

\section{Conclusions and outlook}

569 The use of Bacillus subtilis and Trichoderma spp., and two different composts has been effective in 570 reducing $P$. capsici abundance and the disease severity at both experimental sites in naturally and 
artificial infested soils. In addition, the results have shown that, in general, the Bacillus subtilis and

572 Trichoderma spp. based treatments resulted in a good feedback of the resident Trichoderma spp. and Bacillus spp. communities from rhizosphere. After applied BCA's treatments, the antagonists established itself in soil together with the same resident populations used the nutrients from the organic matter which boosted their population and made them more competitive in the soil. The disease suppression was probably BCA's functionally induced and not controlled by changes in the microbial structure or diversity. The differences in the rhizosphere bacterial community in both sites were not attributed to the treatments, but rather to the soil $\mathrm{pH}$ and to the origin of the pathogen infection. On the other hand, the fungal community was found to depend on the type of rhizosphere as substrate, but was not affected by the modality of plant infection (e.g., naturally or artificially) . However, the complex phenomenon of disease suppressiveness of the studied soils cannot simply

582 be ascribed to a single bacterial or fungal taxon, or group, but is most likely governed by microbial consortia.

These results suggested that the next-generation sequencing approaches is useful to investigate microbial interactions, as essential knowledge may be acquired on the impact that beneficial microorganisms have on non-targeted microbial communities in the rhizosphere, while controlling the pathogen. Thus, the modern approach of this study has highlighted and confirmed the potential of Bacillus subtilis and Trichoderma spp. used alone or in microbial consortia in combination also with organic material, as biocontrol agents for a sustainable management of Phytophthora crown rot of zucchini, since the disease severity was reduced without causing any significant change in the resident microbial communities under the considered field conditions.

\section{Acknowledgements}

594 The project leading to this application has received funding from the European Union's Horizon 5952020 research and innovation programme under grant agreement No 634179 - EMPHASIS. The authors thank Professor Marguerite Jones for the language revision. 


\section{Conflict of Interest}

The authors declare that they have no conflict of interest. Massimo Pugliese declares he has a financial interest (shareholder) in the company AgriNewTech that provided some of the products tested in this study.

\section{References}

Bais, H.P., Fall, R., Vivanco, M., 2004. Biocontrol of Bacillus subtilis against infection of Arabidopsis roots by Pseudomonas syringae is facilitated by biofilm formation and surfactin production. ASPB. 134, 307-319.

Benítez, T., Rincón, A.M., Limón, M.C., Codón, A.C., 2004. Biocontrol mechanisms of Trichoderma strains. Int. Microbiol. 7, 249-260.

Blaya, J., López-Mondéjar, R., Lloret, E., Pascual, J.A., Ros, M., 2013. Changes induced by Trichoderma harzianum in suppressive compost controlling Fusarium wilt. Pestic. Biochem. Phys. 107, 112-119.

Blaya, J., Marhuenda, F., Pascual, J., Ros, M., 2016. Microbiota characterization of compost using omics approaches opens new perspectives for Phytophthora root rot control. PLosONE 11, e0158048.

Bonanomi, G., Antignani, V., Capodilupo, M., Scala, F., 2010. Identifying the characteristics of organic soil amendments that suppress soilborne plant diseases. Soil Biol. Biochem. 42, 136-144.

Bonanomi, G., Giorgi, V., Giovanni, D.S., Neri, B., Scala, F., 2006. Olive mill residues affect saprophytic growth and disease incidence of foliar and soilborne plant fungal pathogens. Agric. Ecosyst. Environ. 115, 194-200.

Bonanomi, G., Lorito, M., Vina,le F., Woo, S.L., 2018. Organic amendments, beneficial microbes and soil microbiota: toward a unified frame work for disease suppression. Annu. Rev. Phytopatol. 56, 1-20.

Cao, F.Y., Yoshioka, K., Desveaux, D., 2011. The roles of ABA in plant - pathogen interactions. J. Plant Res.124, 489-499.

Caporaso, J. G. et al., 2010. QIIME allows analysis of high-throughput community sequencing data. Nat. Meth. 7, 335-336.

Chae, D.H., Jin, R. D., Hwangbo, H., Kim, Y.W., Kim, Y.C., Park, R. D., Krishnan, H.B., Kim, K.Y., 2006. Control of late blight (Phytophthora capsici) in pepper plant with a compost containing multude of chitinase-producing bacteria. BioContr. 51, 339-351.

Charest, M.H., Beauchamp, C.L., Antoun, H., 2005. Effects of the humic substances of deinking paper sludge on the antagonism between two compost bacteria and Pythium ultimum. FEMS Microbiol. Ecol. 5, 219-227.

Chen, J.T., Su, H.J., Huang, J.W., 2012. Isolation and identification of secondary metabolites of Clitocybe nuda responsible for inhibition of zoospore germination of Phytophthora capsici. J. Agr. Food Chem. 60, 7341-7344.

Colla, P., Gilardi, G., Gullino, M.L., 2012. A review and critical analysis of the European situation of soilborne disease management in the vegetable sector. Phytoparasitica 40, 515-523. 
Compant, S., Clément C. and Sessitsch, A.. 2010. Plant growth promoting bacteria in the rhizo and endosphere of plants: Their role, colonization, mechanisms involved and prospects for utilization. Soil Biol. Biochem. 42, 669-678.

Cregger, M.A., Sanders, N.J., Dunn, R.R., Classen, A.T., 2015. Microbial communities respond to experimental warming, but site matters. PeerJ 2, e358.

Cucu, M.A., Marchan, S., Said-Pullicino, D., Celi, L., Kandeler, E., Rasche, F., 2017. Resource driven community dynamics of $\mathrm{NH}_{4}{ }^{+}$assimilating and $\mathrm{N}_{2} \mathrm{O}$ reducing archaea in a temperate paddy soil. Pedobiologia, 62, 16-27.

Cucu, M.A., Gilardi, G., Pugliese, M., Matic, S., Ulrich, G., Gullino, M.L., Garibaldi, A., 2018. Influence of different biological control agents and compost on total and nitrification driving microbial communities at rhizosphere and soil level in a lettuce - Fusarium oxysporum $\mathrm{f}$. sp. lactucae pathosystem. J. App.Microb. doi: 10.1111/jam.14153.

Cucu M.A., Gilardi G., Pugliese M., Gullino M.L., Garibaldi A., 2020. An assessment of the modulation of the population dynamics of pathogenic Fusarium oxysporum $\mathrm{f}$. sp. lycopersici in the tomato rhizosphere by means of the application of Bacillus subtilis QST 713, Trichoderma sp. TW2 and two composts. Biol. Control, 142, 1-10.

Cuesta, G., Garcia-de-la-Fuente, R., Abad, M., and Fornes, F., 2012. Isolation and identification of actinomycetes from a compost-amended soil with potential as biocontrol agents. J. Environ. Manage. 95, S280-S284.

da Costa Ribeiro, C.S. and P.W. Bosland. 2012. Physiological race characterization of Phytophthora capsici isolates from several host plant species in Brazil using New Mexico Recombinant Inbred Lines of Capsicum annuum at two inoculum levels. J. Amer. Soc. Hort. Sci. 137, 421-426.

Dixon, P., 2003. VEGAN, a package of R functions for community ecology. J. Veg. Sci. 14, 927930.

Ezziyyani, M., Requena, M.E., Egea-Gilabert, C., et al., 2007. Biological control of Phytophthora root rot of peppercili using Trichoderma harzianum and Streptomyces rochei in combination. J. Phytopathol. 155, 342-349.

Fierer, N. \& Jackson, R.B., 2006. The diversity and biogeography of soil bacterial communities. P. Natl. Acad. Sci. USA 103, 626-631.

Francis, C.A., Roberts, K.J., Beman, J.M., Santoro, A.E., Oakley, B.B., 2005. Ubiquity and diversity of ammonia-oxidizing archaea in water columns and sediments of the ocean. Proc. Natl. Acad. Sci. USA 102, 14683-14688.

Gao, W., Zhang, W. and Meldrum, D.R., 2011. RT-qPCR based quantitative analysis of gene expression in single bacterial cells. J. Microbiol. Methods, 85, 221-227.

Garcia, J.L., Probanza, A., Ramos, B., Manero, F.J.G., 2011. Ecology, genetic diversity and screening strategies of plant growth promoting rhizobacteria. J. Plant Nutr. Soil Sci. 164,1-7.

Garibaldi, A., \& Gullino, M.L., 2010. Emerging soilborne diseases of horticultural crops and new trends in their management. Acta Horticolturae, 883,37-47.

Garibaldi, A., Guglielmone, L., Gullino, M.L., 1989. Rhizosphere competence of antagonistic Fusaria isolated from suppressive soils. Symbiosis, 9, 401-404

Garibaldi, A., Minuto, A., Grasso, V., Gullino, M.L., 2003. Application of selected antagonistic strains against Phytophthora cryptogea on gerbera in closed soilless systems with disinfection by slow sand filtration. Crop Prot. 22,1053-1061.

Gilardi, G., Baudino, M., Moizio, M., Pugliese, M., Garibaldi, A., Gullino, M. L., 2013. Integrated management of Phytopthora capsici on bell pepper by combining grafting and compost treatment..Crop Prot. 53, 13-19.

Gilardi, G., Demarchi, S., Gullino, M. L., Garibaldi, A., 2015. Nursery treatments with nonconventional products against crown and root rot, caused by Phytophthora capsici, on zucchini. Phytoparasitica, 43, 501-508. 
Gupta, V. K., Schmoll, M., Herrera-Estrella, A., Upadhyay, R. S., Druzhinina I., Tuohy, M.G., 2014. Biotechnology and Biology of Trichoderma. Oxford: Elsevier Science and Technology; 10.1016/C2012-0-00434-6.

Hagn, A., Wallisch, S., Radl, V., Munch, J.C. and Schloter, M., 2007. A new cultivation independent approach to detect and monitor common Trichoderma species in soils. J. Microbiol. Methods, 69, 86-92.

Harman, G.E., 2000. Myths and dogmas of biocontrol: changes in perceptions derived from research on Trichoderma harzianum T-22. Plant Dis. 84 377-393. 10.1094/PDIS.2000.84.4.377.

Harman, G.E., Howell, C.R., Viterbo, A., and Chet, I., 2004. Trichoderma spp. - Opportunistic avirulent plant symbionts. Nat. Rev. Microbiol. 2,43-56.

Hausbeck, M.K., Lamour, K., H., 2004. Phytophthora capsici on vegetable crops: research progress and management challengers. Plant Dis. 88,1292-1303.

Hermosa, R., Viterbo, A., Chet, I., Monte, E., 2012. Plant-beneficial effects of Trichoderma and of its genes. Microbiol. 158,17-25. 10.1099/mic.0.052274-0.

Heydari A., Pessarakli M., 2010. A review on biological control of fungal plant pathogens using microbial antagonists. J. Biol. Sciences, 10, 273-290.

Hoitink, H.A.J., Madden, L.V., Dorrance, A.E., 2006. Systemic resistance induced by Trichoderma spp.: Interactions between the host, the pathogen, the biocontrol agent, and soil organic matter quality. Phytopathol. 96,186-189.

Howell, C.R., 2003. Mechanisms employed by Trichoderma species in the biological control of plant diseases: the history and evolution of current concepts. Plant Dis. 87,4-10.

Huang, X., Chen, L., Ran, W., Shen, Q., Yang, X., 2011. Trichoderma harzianum strain SQR-T37 and its bio-organic fertilizer could control Rhizoctonia solani damping-off disease in cucumber seedlings mainly by the mycoparasitism, Appl. Microbiol. Biotechnol. 91, 741755.

ISTAT, 2017. http://dati.istat.it/

Jeffrey, C., 2001. Cucurbitaceae. In P. Hanelt, ed., Mansfeld's encyclopedia of agricultural and horticultural crops. Springer, Berlin, pp 1510-1557

Jiang, H., Zhang, L., Zhang, J.Z., Ojaghian, M.R., Hyde, K.D., 2016. Antagonistic interaction between Trichoderma asperellum and Phytophthora capsici in vitro. J Zhejiang Univ Sci B. 17, 271-281.

Kang, S. \& Kim, S., 2004. New antifungal activity of penicillic acid against Phytophthora species. Biotech. Letters, 26,695.

Kaur, S., Singh, N., Saudhu, P.S., 2010. In vitro evaluation of Trichoderma viride and T. harzianum against Macrophomina phaseolina causing charcoal root rot of sunflower. Plant Dis. Res. 25,79-89.

Kim, K.D., Nemec, S., Musson, G., 1997. Control of Phytophthora root and crown rot of bell pepper with composts and soil amendments in the greenhouse. Appl. Soil Ecol. 5,109-179.

Kim, S.G., Z. Khan, Y.H. Jeon and Y.H. Kim., 2009. Inhibitory effect of Paenibacillus polymyxa GBR-462 on Phytophthora capsici causing Phytophthora blight in chili pepper. Phytopathol. J. 157, 329-337.

Klindworth, A., Pruesse, E., Schweer, T., Peplies, J., Quast, C., Horn, M., \& Glöckner, F. O., 2013. Evaluation of general 16S ribosomal RNA gene PCR primers for classical and nextgeneration sequencing-based diversity studies. Nucleic acids res., 41(1), e1. doi:10.1093/nar/gks808.

Lamour, K.H., Stam, R., Jupe, J., Huitema, E., 2012. The oomycete broad-host range pathogen Phytophthora capsici. Mol. Plant Path. 13,329-337.

Lan, C.Z., Liu, P.Q., Li, B.J. et al. 2013. Development of a specific PCR assay for the rapid and sensitive detection of Phytophthora capsici. Australasian Plant Pathol. 42, 379-384 https://doi.org/10.1007/s13313-012-0185-8. 
Langarica-Fuentes, A., Zafar, U., Heyworth, A., Brown, T., Fox, G., Robson, G.D., 2014. Fungal succession in an in vessel composting system characterized using 454 pyrosequencing. FEMS Microbiol. Ecol. 88,296-308.

Lauber, C.L., Hamady, M., Knight, R. \& Fierer, N., 2009. Pyrosequencing-based assessment of soil $\mathrm{pH}$ as a predictor of soil bacterial community structure at the continental scale. Appl. Environ. Microbiol. 75,5111-5120.

Lee, K.J., Kamala-Kannan, S., Sub, H.S., Seong, C.K., Lee, G.W., 2008. Biological control of Phytophthora blight in red pepper (Capsicum annuum L.) using Bacillus subtilis. World J. Microbiol. Biotechnol., 24,1139-1145.

Li, H., Cai, X., Gong, J., Xu, T., Ding, G. C., \& Li, J., 2019. Long-term organic farming manipulated rhizospheric microbiome and Bacillus antagonism against pepper blight (Phytophthora capsici). Front. microbiol, 10, 342. doi:10.3389/fmicb.2019.00342.

Lombardi, N., Vitale, S., Turrà, D., Reverberi, M., Fanelli, C., Vinale, F., et al., 2018., Root exudates of stressed plants stimulate and attract Trichoderma soil fungi. Mol. Plant-Microbe Interact. 31, 982-994.

López-Mondèjar, R., Raidl, S., Ros, M., Pascual, .JA., 2010. Quantification of the biocontrol agent Trichoderma harzianum with real-time TaqMan PCR and its potential extrapolation to the hyphal biomass.; Bioresour. Technol. 101, 2888-2891.

Lorito, M., Woo, S. L., 2015b. "Discussion agronomic," in Principles of plant-microbe interactions (ed. Lugtenberg, B.), ed. Berlin: Springer International Publishing, 345-353, 10.1007/978-3319-08575-3_36.

Lorito, M., Woo, S.L., 2015a. "Trichoderma: a multi - purpose toll for integrated pest management", in Principles of plant-microbe interactions (ed. Lugtenberg, B.), ed. Berlin: Springer International Publishing.

Lorito, M., Woo, S.L., Harman, G.E., Monte, E., 2010. Translational research on Trichoderma: from 'omics to the field. Annu. Rev. Phytopathol. 48,395-417.

Magoc, T. and Salzberg, S.L., 2011. FLASH.: Fast length adjustment of short reads to improve genome assemblies. Bioinfo. 27,2957-2963.

McKellar, M.E., Nelson, E.B., 2003. Compost-induced suppression of Pythium damping-off is mediated by fattyacid-metabolizing seed-colonizing microbial communities. Appl. Environ. Microbiol. 69,452-460.

Mendes, R., Garbeva, P., Raaijmakers, J.M., 2013. The rhizosphere microbiome: significance of plant beneficial, plant pathogenic, and human pathogenic microorganisms. FEMS Microb. Rev. 37, 634-663.

Mota-Gutierrez J., Ferrocino, I., Rantsiou K., Cocolin L., 2019 Metataxonomic comparison between internal transcribed spacer and $26 \mathrm{~S}$ ribosomal large subunit (LSU) rDNA gene. Int. J. Food Microbiol., 290, 132-140 .

Muchovej, J.J., Maffia, L.A., Muchovej, R.M.C., 1980. Effect of exchangeable soil aluminium and alkaline calcium salts on the pathogenicity and growth of Phytophthora capsici from green pepper. Phytopathol. 70, 1212-1214.

Naing, K.W., Anees, M., Nguyen X.H., Lee Y.S., Jeon, S.W., Kim S.J., Kim, M.H., Kim K.Y., 2014. Biocontrol of late blight disease (Phytophthora capsici) of pepper and the plant growth promotion by Paenibacillus ehimensis KWN38, J. Phytopathol1. 62, 367-376.

Nguyen, X.-H., Naing, K.-W., Lee, Y.-S., Tindwa, H., Lee, G.-H., Jeong, B.-K., Ro, H.-M., Kim, S.-J., Jung, W.-J., Kim, K.-Y., 2012. Biocontrol potential of Streptomyces griseus H7602 against root rot disease (Phytophthora capsici) in pepper. Plant Pathol. J. 28, 282-289.

Nicol G. W., Leininger S., Schleper C., Prosser J. I., 2008. The influence of soil pH on the diversity, abundance and transcriptional activity of ammonia oxidizing archaea and bacteria. Environ. Microbiol. 10, 2966-2978.

Noble R., Coventry E., 2005. Suppression of soil-borne plant diseases with composts: a review. Biocon. Sci. Technol.15, 3-20. 
Nunez-Zofio, M., Larregla, S., Garbisu, C., 2011. Application of organic amendments followed by soil plastic mulching reduces the incidence of Phytophthora capsici in pepper crops under temperate climate. Crop Prot. 30, 1563-1572.

Olsen, S., Cole, C., Watanabe, F. and Dean, L., 1954. Estimation of available phosphorus in soils by extraction with sodium bicarbonate. USDA Circular Nr 939. Washington, DC: US Gov. Print. Office.

Padley, L.D., Jr. Kabelka, E.A., Roberts, P., French, R., 2008. Evaluation of Cucurbita pepo accessions for crown rot resistance to isolates of Phytophthora capsici. Hort Sci. 43,19961999.

Paris, H.S. and Maynar, D.N., 2008. Cucurbita spp., squash, pumpkin, gourds. In Janick, J. and Paull, R.E eds. The encyclopedia of fruits and nuts. CAB International, Wallingford, Oxforshire, United Kingdom, pp. 292-299.

Parra, G., Ristaino, J.B., 2001. Resistance to mefenoxam and metalaxyl among field isolates of Phytophthora capsici causing Phytophthora blight of bell pepper. Plant Dis. 85,1069-1075.

Philippot, L., Raaijmakers, J. M., Lemanceau, P., van den Putten, W.H., 2013. Going back to the roots: the microbial ecology of the rhizosphere. Nat. Rev. Microbiol. 11,789-799.

Ploetz, R.C., Heine, G., Haynes, J., Watson, M., 2002. An investigation of biological attributes that may contribute to the importance of Phytophthora capsici as a vegetable pathogen in Florida. Ann. Appl. Biol. 140, 61-67.

Postma, J., Schilder, M.T. \& van Hoof, R.A., 2011. Indigenous populations of three closely related Lysobacter spp. in agricultural soils using real-time PCR. Microb. Ecol. 62, 948-958.

Pugliese, M., Liu, B.P., Gullino, M.L. and Garibaldi, A., 2011. Microbial enrichment of compost with biological control agents to enhance suppressiveness to four soil-borne diseases in green house. J. Plant Dis. Protect. 118, 45-50.

Pugliese, M., Gilardi, G., Garibaldi, A., Gullino, M. L., 2015. Organic amendments and soil suppressiveness: results with vegetable and ornamental crops. In: Organic amendments and soil suppressiveness in plant disease management (Meghvansi M. K. and Varma A. coord.), Soil Biology 46, Springer, 495-509.

Ros, M., Raut, I., Santisima-Trinidad, A.B., Pascual, J.A., 2016. Relationship of microbial communities and suppressiveness of Trichoderma fortified composts for pepper seedlings infected by Phytophthora nicotianae. PLoS One, 12(3), e0174069, doi: 10.1371/journal.pone.0174069.

Rotthauwe, J.H., Witzel, K.P., Liesack, W., 1997. The ammonia monooxygenase structural gene amoA as a functional marker: molecular fine-scale analysis of natural ammonia oxidizing populations. Appl. Environ. Microbiol. 63, 4704-4712.

Rousk, J., Bååth, E., Brookes, P.C., et al., 2010. Soil bacterial and fungal communities across a pH gradient in an arable soil. ISME J. 4, 1340-1351.

Sang, M. K., Kim, J.G., Kim, K.D., 2010. Biocontrol activity and induction of systemic resistance in pepper by compost water extracts against Phytophthora capsici. Phytopathol. 100, 774783.

Sang, M. K., Shrestha, A., Kim, D. Y., Park, K., Pak, C. H., \& Kim, K. D., 2013. Biocontrol of Phytophthora blight and anthracnose in pepper by sequentially selected antagonistic rhizobacteria against Phytophthora capsici. Plant Phatol. J., 9, 154-167.

Sang, M.K., Chun, S. and Kim, K.D., 2008. Biological control of Phytophthora blight of pepper by antagonistic rhizobacteria selected from a sequential screening procedure. Biol. Control, 46, 424-433.

Segarra, G., Avilés, M., Casanova, E., Borrero, C., Trillas, I., 2013. Effectiveness of biological control of Phytophthora capsici in pepper by Trichoderma asperellum strain T34. Phytopathol. Mediterr. 52, 77-83. 
Segarra, G., Casanova, E,. Bellido, D,. Odena, M.A,. Oliveira, E and Trillas, I., 2007. Proteome, salicylic acid, and jasmonic acid changes in cucumber plants inoculated with Trichoderma asperellum strain T34. Proteomics 7, 3943-3952.

Sid, A., Ezziyyani, M., Egea-Gilabert, C., Candela, M., 2003. Selecting bacterial strains for use in the biocontrol of diseases caused by Phytophthora capsici and Alternaria alternata in sweet pepper plants, Biol. Plant. 47, 569-574.

Soil Survey Staff, 2010. Keys to Soil Taxonomy, 11th ed. USDA-Natural Resources Conservation Service, Washington, DC.

Spadaro, D., Gullino, M.L., 2005. Improving the efficacy of biocontrol agents against soil-borne pathogens. Crop Prot. 24, 601-613.

Steger, K., Jarvis, A., Smars, S., Sundh, I., 2003. Comparison of signature lipid methods to determine microbial community structure in compost. J. Microbiol. Methods., 55, 371-382. PMID: 14529958.

Sutherland, E.D., Papavizas, G.C., 1991. Evaluation of oospore hyperparasites for the control of Phytophthora crown rot of pepper. J. Phytopathol. 131, 33-39.

Sy, O., Steiner, R., Bosland, P.W., 2008. Recombinant inbred line differential identifies racespecific resistance to Phytophthora root rot in Capsicum annum. Phytopathol. 98, 867-870.

Tamietti, G., Valentino, D., 2001. Physiological characterisation of a population of Phytophthora capsici Leon. from Northern Italy. J. Plant Path. 83, 199-205.

Tandon, A., Fatima, T., Gautam, A., Yadav, U., Srivastava, S., Singh, P.C., 2018. Effect of Trichoderma koningiopsis on Chickpea rhizosphere activities under different fertilization regimes. Open J. Soil Sc., 8, 261-275.

Thampi, A., Bhai, R.S., 2017. Rhizosphere actinobacteria for combating Phytophthora capsici and Sclerotium rolfsii, the major soil borne pathogens of black pepper (Piper nigrum L.). Biol. Control 109:1-13. doi:https://doi.org/10.1016/j.biocontrol.2017.03.006.

Thébault, E., Fontaine, C., 2010. Stability of ecological communities and the architecture of mutualistic and trophic networks. Science. 329, 853-856.

Verma, M., Brar, S.K., Tyagi, R.D., Surampalli, R.Y., Valéro, J.R., 2007. Antagonistic fungi, Trichoderma spp.: Panoply of biological control. Biochem. Eng. J. 37,1-20.

Vinale, F., Sivasithamparam, K., Ghisalberti, E.L., Marra, R., Barbetti, M.J., Li, H., et al., 2008. A novel role of Trichoderma secondary metabolites in the interaction with plants. Physiol. Mol. Plant. Pathol. 72, 80-86.

Wallenstein, M.D., 2017. Managing and manipulating the rhizosphere microbiome for plant health: a system approach. Rhizosphere, 3, 230-232.

Wang, Z., Johnston, P.R., Takamatsu, S., Spatafora, J.W., Hibbett, D.S., 2006. Toward a phylogenetic classification of the Leotiomycetes based on rDNA data. Mycologia, 98, 10651075.

Wei, Z., Yang, X., Yin, S., Shen, Q., Ran, W., Xu, Y., 2011. Efficacy of Bacillus-fortified organic fertiliser in controlling bacterial wilt of tomato in the field, Appl. Soil Ecol. 48, 152-159.

Woo, S.L., Ruocco, M., Vinale, F., Nigro, M., Marra, R., Lombardi, N., 2014. Trichoderma based products and their widespread use in agriculture. Open Mycol. J. 8,71-126.

Woo, S.L., Scala, F., Ruocco, M., Lorito, M., 2006. The molecular biology of the interactions between Trichoderma spp., phytopathogenic fungi, and plants. Phytopathol. 96,181-185.

Yang, M.M., Xu, L.P., Xue, Q.Y., Yang, J.H., Xu, Q., Liu, H.X., Guo, J.H., 2012. Screening potential bacterial biocontrol agents towards Phytophthora capsici in pepper, Eur. J. Plant Pathol. 1-10.

Yuan, J., Raza, W., Shen, Q., Huang, Q., 2012. Antifungal activity of Bacillus amyloliquefaciens NJN-6 volatile compounds against Fusarium oxysporum f. sp cubense. Appl. Environ. Microbiol. 78, 5942-5944. 
889 Zhang, S., White, T.L., Martinez, M.C., McInroy, J.A., Kloepper, J.W., Klassen, W., 2010. 890 Evaluation of plant growth-promoting rhizobacteria for control of Phytophthora blight on 891 squash under greenhouse conditions. Biol Control, 53, 129-135. 


\section{$916 \quad$ Figure Captions}

917 Figure 1 Boxplots of the $\alpha$-diversity measures of microbiota (Panel A) and mycobiota (Panel B) of 918 the soils. Boxplot display Chao1 index, estimating the number of different taxa, Shannon diversity 919 index evaluating the taxa richness as well as number of OTUs observed. The bars are color-coded 920 according to the site and the sampling year. Individual points and brackets represent the richness 921 estimate and the theoretical standard error range, respectively.

922

923 Figure 2 Principal coordinate analysis of the Unweighted UniFrac distances of the 16S rRNA gene 924 sequence data. The samples are color-coded according to the site and the sampling year 